\title{
ANALISA FAKTOR WAKTU PULIH SADAR PASIEN POST LAPARATOMI ANESTESI UMUM
}

\author{
Risdayati $^{1}$, Fitrian Rayasari ${ }^{2}$, Siti Badriah ${ }^{3}$ \\ Universitas Muhammadiyah Jakarta ${ }^{1,2}$ \\ Politeknik Kesehatan Kementerian Kesehatan Tasikmalaya ${ }^{3}$ \\ risdayati72risdayati@gmail.com ${ }^{1}$
}

\begin{abstract}
ABSTRAK
Penelitian ini bertujuan untuk menganalisis faktor dominan yang berhubungan dengan waktu pulih sadar pasien laparatomi, anestesi umum di Recovery Room RS Bhayangkara Tk I Jakarta. Metode Penelitian yang digunakan adalah penelitian analitik dengan pendekatan crosssectional. Hasil penelitian menunjukkan ada hubungan usia dengan waktu pulih sadar post laparatomi anestesi umum $(\mathrm{p}=0,028)$. Ada perbedaan antara jenis kelamin dengan waktu pulih sadar pasien laparatomi anestesi umum $(p=0,04)$. Ada perbedaan antara ASA dengan waktu pulih sadar pasien laparatomi anestesi umum $(\mathrm{p}=0,01)$. Ada hubungan antara IMT dengan waktu pulih sadar pasien laparatomi anestesi umum ( $\mathrm{p}=0,0005)$. Tidak ada hubungan antara suhu tubuh, lama puasa dan lama operasi dengan masing-masing nilai $\mathrm{p}(0,59,0,6$ dan 0,94$)$. Simpulan, faktor dominan yang mempengaruhi waktu pulih sadar pasien post laparatomi anestesi umum adalah suhu tubuh yaitu hipotermi.
\end{abstract}

Kata Kunci : Anestesi, Laparatomi, Pulih Sadar, Thermoregulasi

\begin{abstract}
This study aims to analyze the dominant factors associated with the time to recover consciousness of patients with laparotomy, general anesthesia in the Recovery Room of Bhayangkara Hospital Tk I Jakarta. The research method used is analytical research with a cross-sectional approach. The results showed a relationship between age and recovery time after general anesthesia post-laparotomy $(p=0.028)$. There was a difference between the sexes and the time to recover consciousness of the laparotomy patients with general anesthesia $(p=0.04)$. There was a difference between ASA and recovery time of conscious laparotomy patients with general anesthesia $(p=0.01)$. There was a correlation between $B M I$ and awake in patients with available anesthesia laparotomy $(p=0.0005)$. There was no relationship between body temperature, fasting time, and duration of operation with $p$ values $(0.59,0.6$, and 0.94), respectively. In conclusion, the dominant factor that affects the recovery time of consciousness in post-laparotomy general anesthesia patients is body temperature, namely hypothermia.
\end{abstract}

Keywords: Anesthesia, Laparotomy, Conscious Recovery, Thermoregulation

\section{PENDAHULUHAN}

Anestesi umum adalah suatu keadaan reversibel yang mengubah status fisiologis tubuh, ditandai dengan hilangnya kesadaran (sedasi), hilangnya persepsi nyeri (analgesia), hilangnya memori (amnesia) dan relaksasi (Supriady et al., 2018). Anestesi 
umum dapat juga menyebabkan pasien akan kehilangan sensasi dan mengalami amnesia ketika pembedahan berlangsung (Hanifa et al., 2017).

Pulih sadar dari anestesi umum dapat didefinisikan juga sebagai suatu kondisi tubuh dimana konduksi neuromuskular, refleks protektif jalan nafas dan kesadaran telah kembali setelah dihentikannya pemberian obat-obatan anestesi dan proses pembedahan juga telah selesai. Proses pulih sadar dari anestesi harus diawasi seksama dan kondisi pasien harus dinilai ulang sebelum pasien bisa dipindahkan ke ruang perawatan (Permatasari et al., 2017). Rerata waktu pemulihan dilakukan University of Iowa, USA 112 menit dan di Rumah Sakit Umum Shin- yurigaoka, Kawasaki, Jepang 22 menit (Thenuwara et al., 2018).

Proses pulih sadar yang tertunda merupakan salah satu kejadian yang tidak diharapkan dalam anestesi, penyebabnya berbagai faktor. Bisa disebabkan oleh faktor pasien, masalah dalam pembedahan dan anestesi serta faktor obat-obatan. Faktor penyebab yang terkait anestesi bisa karena faktor farmakologis ataupun faktor nonfarmakologis. Yang termasuk faktor nonfarmakologis adalah hipotermia, hipotensi, hipoksia dan hipercapnia. Faktor pasien misalnya usia lanjut, jenis kelamin, obesitas, faktor genetik dan penyakit penyerta (disfungsi organ jantung, ginjal dan hepar) yang dapat meningkatkan potensi obat-obat anestesi yang diberikan. Faktor penyebab yang terkait pembedahan adalah lamanya operasi dan teknik anestesi yang dilakukan (Permatasari et al., 2017).

Penelitian yang dilakukan Olfah et al., (2019) yang mempengaruhi waktu pulih sadar adalah umur, jenis kelamin, pekerjaan, pendidikan, ASA, dan ROM. Penelitian Sommeng (2019) menunjukkan bahwa status fisik pra anestesi umum dalam kriteria ASA (American Society of Anesthesiology) dapat mempengaruhi waktu pulih pasien pasca operasi. Penelitian oleh Mamuasa et al., (2018) menunjukkan bahwa faktor-faktor yang berhubungan dengan waktu pulih sadar yaitu : usia, lama operasi, status fisik, jenis obat anestesi dan derajat hipertensi. Penelitian lain juga menyebutkan bahwa faktor yang berhubungan waktu pulih sadar pada penelitian mereka jenis kelamin, umur, jenis operasi, Indeks Massa Tubuh (IMT), lama anestesi, yang mempengaruhi waktu pulih sadar antara lain pengaturan posisi (Delima et al., 2019; Olfah et al., 2019).

Penelitian faktor yang berhubungan dengan waktu pulih sadar pasca anestesi umum pada pasien laparatomi di RS Bhayangkara Tk. I R. Said Sukanto Jakarta selama ini belum pernah diteliti sehingga belum mendapatkan data secara pasti. Selain itu penelitian sebeumnya hanya meneliti faktor seperti umur, jenis kelamin, pekerjaan, pendidikan, dll. Namun pada penelitian ini faktor yang ditambahkan untuk diteliti adalah IMT, suhu tubuh, lama puasa dan lama operasi.

\section{METODE PENELITIAN}

Responden yang sesuai dengan kriteria inklusi, berusia $>17$ tahun, post laparatomi dengan anestesi umum, ASA 1 dan ASA 2 diberikanpenjelasan tentang prosedur yang akan dijalani, menandatangani surat persetujuan (informed consent). Tidak mengalami komplikasi pada saat operasi dan setelah pasca anestesi umum dan tdak menderita Covid-19, akhirnya diperoleh jumlah sampel 78 orang.

Data diambil dengan menggunakan lembar observasi melalui studi dokumentasi dan observasi. Pasien post laparatomi dengan anestesi umum dilakukan ekstubusi saat itu di mulai penghitungan waktu pulih sadar dengan mengunakan stopwatch, diukur temperatur tubuh, pantau tekanan darah non-invasif, elektrokardiografi (EKG), dan pulse oksimetri, dilanjutkan penilaian Modified Aldret Score $\geq 9$. 
Berdasarkan data yang didapat, kemudian dilakukan analisis univariat, analisis bivariat analisa multivariat menggunakan regresi linear ganda.

\section{HASIL PENELITIAN}

Tabel. 1

Distribusi Responden Berdasarkan Usia, IMT, Suhu Tubuh, Lama Puasa, Lama Operasi, Jenis Kelamin, ASA dengan Lama Waktu Pulih (n-78)

\begin{tabular}{lcccccc}
\hline Variabel & $\mathrm{N}$ & $\%$ & Rata-Rata & SD & Range & p-Value \\
\hline Usia (Tahun) & & & 41,06 & 14,14 & $18-81$ & 0,028 \\
IMT $\left(\mathrm{kg} / \mathrm{m}^{2}\right)$ & & & 23,40 & 3,70 & $17,8-34,6$ & 0,000 \\
Suhu Tubuh $\left({ }^{0} \mathrm{C}\right)$ & & & 35,65 & 0,47 & $34-36,4$ & 0,059 \\
\hline Lama Puasa (Jam) & & & 9,00 & 1,997 & $6-14$ & 0,60 \\
Lama Operasi (Jam) & & & 1,50 & 0,68 & $1-3$ & \\
Waktu Pulih Sadar & & & 7,495 & 4,95 & $4,33-26,25$ & 0,940 \\
(Menit & & & & & & 0,040 \\
Jenis Kelamin & 46 & 59 & & & & \\
Laki-Laki & 32 & 41 & & & & 0,040 \\
Perempuan & & & & & & \\
\hline ASA & 29 & 37,2 & & & & \\
ASA 1 & 49 & 62,8 & & & & \\
ASA 2 & & & &
\end{tabular}

Berdasarkan tabel 1 terlihat bahwa rata-tara responden berusia 41,06 tahun dengan SD 14,14. Berdasarkan uji Pearson didapatkan hasil ada hubungan yang bermakna antara usia dengan waktu pulih sadar $(\mathrm{p}=0,028, \alpha=0,05)$. Rata-rata IMT responden 23,40 dengan SD 3,70, Berdasarkan uji Spearman didapatkan hasil ada hubungan yang bermakna antara IMT dengan waktu pulih sadar $(\mathrm{p}=0,000, \alpha=0,05)$. Suhu tubuh ratarata 35,63 dengan SD 0,47.

Berdasarkan uji Spearman didapatkan hasil tidak ada hubungan yang bermakna antara temperatur tubuh dengan waktu pulih sadar $(\mathrm{p}=0,059, \alpha=0,05)$. Lama puasa ratarata 9 jam dengan SD 1,997, lama operasi 1,50 jam dengan SD 0,68 dan waktu pulih sadar rata-rata 7,495 jam dengan SD 4,95. Rata-rata responden berjenis kelamin laki-laki yaitu sebanyak 46 responden (59\%).

Berdasarkan uji t Mann Whitney dengan 95\% CI didapatkan hasil ada perbedaan yang bermakna antara jenis kelamin dengan waktu pulih sadar $(\mathrm{p}=0,040, \alpha=0,05)$. ASA mayoritas merupakan ASA 2 yaitu sebanyak 49 responden (62,8\%). Berdasarkan uji $\mathrm{t}$ Mann Whitney dengan 95\% CI didapatkan hasil ada perbedaan yang bermakna antara ASA dengan waktu pulih sadar $(\mathrm{p}=0,040, \alpha=0,05)$.

Tabel. 2

Pemodelan Akhir Analisis Multivariat Faktor-Faktor yang Berhubungan dengan Waktu Pulih Sadar $(\mathrm{n}=78)$

\begin{tabular}{lccccc}
\hline \multicolumn{1}{c}{ Variabel } & $\begin{array}{c}\text { Koefisien } \\
(\mathrm{B})\end{array}$ & S.E & $\begin{array}{c}\text { Koefisien } \\
\text { Korelasi }\end{array}$ & $\mathrm{T}$ & p-value \\
\hline Konstanta & 107,637 & 31,596 & & 3,407 & 0,001 \\
Usia (Tahun) & 0,078 & 0,030 & 0,240 & 2,615 & 0,011 \\
IMT & 0,588 & 0,113 & 0,474 & 5,193 & 0,000 \\
Temperatur & $-3,253$ & 0,889 & $-0,335$ & $-3,657$ & 0,000 \\
\hline
\end{tabular}


Koefisien determinasi (R Square) nilai 0,388 artinya bahwa model regresi yang diperoleh variabel temperatur, IMT dan usia dapat menjelaskan variasi variabel waktu pulih sadar sebesar $38,8 \%$.

\section{PEMBAHASAN}

Dalam penelitian ini selain didapatkan faktor-faktor yang berhubungan dengan waktu pulih sadar pasien post laparatomi anestesi umum, juga mendapatkan faktor dominan yang mempengaruhi waktu pulih sadat. Dari hasil penelitian menunjukkan terdapat hubungan yang bermakna antara usia dengan waktu pulih sadar, hubungan yang lemah dan berpola positif artinya semakin tinggi usia pasien semakin lama waktu pulih sadarnya. Didukung hasil penelitian dari Banerjee et al., (2018) yang menunjukkan bahwa usia yang lebih tua telah dilaporkan menjadi faktor risiko penting untuk tertunda pemulihan. Dalam beberapa penelitian yang dapat menjelaskan bahwa perubahan fisiologis pada orang tua di mana metabolisme obat berkepanjangan menyebabkan pemulihan tertunda (Permatasari et al., 2017). Berbeda dengan penelitian oleh Wardana et al., (2019) menyimpulkan waktu pulih sadar pada pasien operasi menggunakan anastesi umum propofol di Rumah Sakit Ibnu Sina Makassar berdasarkan usia tidak mempengaruhi waktu pulih sadar.

Sesuai dengan teori pada usia lanjut akan terjadi peningkatan sensitifitas terhadap obat-obatan anestesi, golongan opioid dan benzodiazepine karena penurunan fungsi susunan syaraf pusat. Bisa disebabkan karena dosis yang berlebihan dan metabolisme obat yang menurun pada usia lanjut (Permatasari et al., 2017).

Hasil penelitian menunjukkan terdapat hubungan yang bermakna antara IMT (Indeks Massa Tubuh) dengan waktu pulih sadar, hubungan yang sedang dan berpola positif artinya semakin tinggi IMT pasien semakin lama waktu pulih sadarnya. Didukung dengan penelitian sebelumnya yang menyatakan terdapat hubungan antara Indeks Massa Tubuh denga waktu pulih sadar (Olfah et al., 2019). Didukung juga penelitian dari Azmi et al., (2019) menyimpulkan terdapat hubungan indeks massa tubuh dengan waktu pulih sadar pada pasien post operasi dengan general anestesia di Recovery Room RSUD Bangil.

Pada pasien obesitas terjadi peningkatan konsumsi oksigen dan peningkatan produksi karbondioksida, akan tetapi basal metabolik rate tetap normal karena berhubungan dengan luasnya permukaan tubuh Penurunan volume cadangan ekspirasi dan penurunan Fraction Residual Capasity (FRC) terjadi pada posisi pasin tegak lurus sehingga tidal volume normal tidak terpenuhi, efek ini diperparah bila pasien dalam posisi terlentang. Hasil dari ini adalah kelainan ventilasi dan perfusi, shunting dari kiri ke kanan, dan hipoksemia. Elastisitas dinding dada berkurang pada obesitas, walaupun elastisitas paru-paru tidak berubah. Fungsi pernapasan, seperti kapasitas vital paksa, volume ekspirasi paksa, dan arus ekspirasi puncak, tidak berubah dalam obesitas. Seiring dengan meningkatnya obesitas, sindrom hipoventilasi dapat terjadi. Ini dicirikan dengan hilangnya dorongan hiperkapnia, apnea tidur, hypersomnolence, dan kesulitan saluran udara. Ini dapat berkembang menjadi sindrom Pickwickian (hiperkarbia, hipoksia, polycytemia, hypersomnolence, hipertensi paru, dan kegagalan biventricular).

Hasil penelitian menunjukkan tidak terdapat hubungan yang bermakna antara termpeatur dengan waktu pulih sadar. Namun ketika dilakukan uji multivariat terlihat bahwa nilai koefisien termoregulasi adalah - 3,253, sehingga dapat disimpulkan bahwa setiap kenaikan termoregulasi sebesar $1^{\circ} \mathrm{C}$ maka akan menurunkan (mempercepat) waktu pulih sadar sebesar 3.036 detik, sehinga semakin rendah termperatur tubuh maka waktu pulih sadar akan semakin lama. 
Hipotermia perioperatif akan memengaruhi metabolisme berbagai obat- obatan anestesia yang disebabkan enzim- enzim yang mengatur fungsi organ dan juga durasi obat yang sangat sensitif terhadap perubahan suhu. Hipotermia ringan dapat mengganggu profil farmakokinetik propofol dan juga meningkatkan durasi kerja atrakurium, vekuronium, serta pankuronium. Kadar propofol plasma akan meningkat $30 \%$ pada saat penurunan suhu inti $3^{\circ} \mathrm{C}$ di bawah normal. Hipotermia juga akan memengaruhi farmakodinamik obat anestesia inhalasi.

Kelarutan obat anestesia inhalasi di dalam plasma akan meningkat, sehingga saat dalam keadaan equilibrium, obat yang terdistribusi di dalam tubuh akan lebih banyak. Peningkatan kelarutan anestesia inhalasi serta pemanjangan durasi kerja pelemas otot diduga merupakan penyebab lambatnya pasien bangun pada saat akhir anestesia. Masa perawatan saat di ruang pemulihan rata-rata menjadi bertambah pada pasien hipotermia. Hasil penelitian menunjukkan terdapat hubungan yang bermakna antara ASA dengan waktu pulih sadar. Secara klinis terdapat perbedaan bermakna waktu pulih sadar responden ASA 1 dan ASA 2. Didukung penelitian yang dilakukan Sommeng (2019) yang menunjukkan bahwa adanya hubungan antara status fisik pra anestesi umum dengan waktu pulih pasien pasca operasi mastektomi. Untuk menentukan prognosis ASA (American Society of Anesthesiologists) membuat klasifikasi berdasarkan status fisik pasien pra anestesi yang membagi pasien ke dalam 5 kelompok atau kategori sebagai berikut: ASA I, yaitu pasien dalam keadaan sehat yang memerlukan operasi. ASA II, yaitu pasien dengan kelainan sistemik ringan sampai sedang baik karena penyakit bedah maupun penyakit lainnya.

Evaluasi pra anestesi pada dasarnya bertujuan untuk mengurangi morbiditas dan mortalitas perioperatif dan untuk menghilangkan kecemasan pasien. Evaluasi ini juga bermanfaat dalam membangun hubungan baik antara dokter dan pasien, mengetahui kelainan bedah yang dialami pasien dan gangguan kesehatan lain yang menyertainya, untuk menyusun rencana perawatan anestesi perioperatif, dan memberikan informed consent untuk rencana anestesi. Evaluasi ini juga meliputi konsultasi mengenai riwayat penyakit pasien, dan penjelasan mengenai pilihan jenis anestesi dan obat- obatan yang digunakan serta keuntungan dan kerugian dari masing-masing jenis anestesi dan memprediksi komplikasi pasca anestesi tersebut (Wardana et al., 2019)

Hasil penelitian menunjukkan tidak terdapat hubungan yang signifikan antara lama puasa pra anestesi dengan waktu pulih sadar. Ini bisa dipahami karena ketika pasien mulai puasa maka IVFD dipasang dan diberi cairan infus sesuai dengan kebutuhan pasien. Kemungkinan terjadi dehidrasi bisa dihindari. Didukung dengan penelitian dari Wardana et al., (2019) menyimpulkan waktu pulih sadar pada pasien operasi menggunakan anastesi umum propofol di Rumah Sakit Ibnu Sina Makassar berdasarkan durasi puasa tidak mempengaruhi waktu pulih sadar. Saat pasien mulai puasa, pasien dipasang infus di tangan, kemudian diberikan cairan Ringer laktat sebanyak $10 \mathrm{~mL} / \mathrm{kgBB}$ untuk mengganti kehilangan cairan selama puasa (Arvianto et al., 2017).

Hasil penelitian menunjukkan tidak terdapat hubungan yang signifikan antara lama waktu operasi dengan waktu pulih sadar. Pada penelitian oleh Imelda et al., (2018) hubungan yang bermakna antara lama operasi $\geq 3$ jam dengan dan kejadian hipoalbuminemia pasca bedah pada pasien karsinoma kolorektal. 


\section{SIMPULAN}

Indeks Massa Tubuh (IMT), thermoregulasi dan usia memiliki konstribusi terhadap waktu pulih sadar post laparatomi dengan anestesi umum. Faktor dominan yang mempengaruhi waktu pulih sadar pasien post laparatomi anestesi umum adalah suhu tubuh yaitu hipotermi

\section{SARAN}

Maka perlu diperhatikan untuk intervensi bila terjadi hipotermi perencanaan asuhan keperawatan perioperatif khususnya pasien dengan laparatomi dengan anestesi umum. Dianjurkan agar sering tubuh pemantauan suhu dan harus diberikan oksigen, elemen penghangat intravena, selimut penghangat dan topi wol. Penelitian ini dapat perdalam lagi dengan penelitian kuantitatif.

\section{DAFTAR PUSTAKA}

Arvianto, A., Oktaliansah, E., \& Surahman, E. (2017). Perbandingan antara Sevofluran dan Propofol Menggunakan Total Intravenous Anesthesia Target Controlled Infusion terhadap Waktu Pulih Sadar dan Pemulangan Pasien pada Ekstirpasi Fibroadenoma Payudara. Jurnal Anestesi Perioperatif, 5(1), 47-54. https://doi.org/10.15851/jap.v5n1.1002

Azmi, D. A., Wiyono, J., \& Dtn, I. (2019). Relationship of Body Mass Index (BMI) and Type of Operation With Time of Conscious Recover in Postoperative Patients With General Anesthesia at Recovery Room of Bangil Hospital. Jurnal Keperawatan Terapan (e-Journal), 05(02), 2442-6873. http://ojs.poltekkesmalang.ac.id/index.php/JKT/article/view/991

Banerjee, S., Kohli, P., \& Pandey, M. (2018). A Study of Modified Aldrete Score and Fast-Track Criteria for Assessing Recovery from General Anaesthesia after Laparoscopic Surgery in Indian Adults. Perioperative Care and Operating Room Management, 12(1), 39-44. https://doi.org/10.1016/j.pcorm.2018.10.001

Delima, M., Kartika, K., \& Deswita, D. (2019). Pengaruh Pengaturan Posisi terhadap Lama Pemulihan Keadaan Pasien Post Operasi dengan Anestesi Umum di Recovery Room RSAM Bukittinggi. Jurnal Kesehatan Perintis (Perintis's Health Journal), 6(1), 1-10. https://doi.org/10.33653/jkp.v6i1.206

Hanifa, A., Hendarsih, S., \& Jonsu, J. D. T. (2017). Hubungan Hipotermi dengan Waktu Pulih Sadar Pasca General Anestesi di Ruang Pemulihan RSUD Wates. Jurnal Ilmiah Keperawatan, 1(1), 2-3. http://eprints.poltekkesjogja.ac.id/id/eprint/415

Imelda, E. C., Golden, I. N., \& Sudartana, I. K. (2018). Umur 60 Tahun ke Atas dan Lama Operasi 3 Jam ke Atas Merupakan Faktor Risiko Terjadinya Hipoalbuminemia Pasca Bedah pada Pasien Karsinoma Kolorektal. Medicina, 49(1), 42-47. https://doi.org/10.15562/medicina.v49i1.261

Mamuasa, P. P., Mendri, N. K., \& Ernawan, B. (2018). Hubungan Derajat Hipertensi dengan Pemenjangan Waktu Pulih Sadar Pasien Pasca Anestesi Umum di RS PKU Mukammadiyah Yogyakarta [Politeknik Kesehatan Yogyakarta]. http://eprints.poltekkesjogja.ac.id/3679/1/Awal.pdf

Olfah, Y., Andisa, R., \& Jitowiyono, S. (2019). The Relation of Body Mass Index and Duration of Anesthesia with Conscious Recovery Time in Children with General Anesthesia in Regional General Hospital Central Java Kebumen. Journal of Health, 6(1), 58-64. https://doi.org/10.30590/vol6-no1-p58-64 
Permatasari, E., Lalenoh, Diana, C., \& Rahardjo, S. (2017). Pulih Sadar Pasca Anestesi yang Tertunda. Jurnal Neuroanestesi Indonesia, 6(3), 187-194. https://doi.org/10.24244/jni.vol6i3.48

Sommeng, F. (2019). Hubungan Status Fisik Pra Anestesi Umum dengan Waktu Pulih Sadar Pasien Pasca Operasi Mastektomi di RS Ibnu Sina Februari - Maret 2017. UMI Medical Journal, 3(1), 47-58. https://doi.org/10.33096/umj.v3i1.34

Supriady, A., Nasution, A. H., \& Ihsan, M. (2018). Efek Aminophylline Intravena untuk Mempercepat Waktu Pulih Sadar Pasca General Anestesi pada Pasien Pembedahan Laparatomi dengan Menggunakan Bispectral Index di RSUP Haji Adam Malik Medan [Universitas Sumatera Utara]. http://repositori.usu.ac.id/handle/123456789/8283

Thenuwara, K. N., Yoshimura, T., Nakata, Y., \& Dexter, F. (2018). Time to Recovery after General Anesthesia at Hospitals with and Without A Phase I Post-Anesthesia Care Unit: A Historical Cohort Study. Canadian Journal of Anesthesia, 65(12), 1296-1302. https://doi.org/10.1007/s12630-018-1220-1

Wardana, R. N. P., Sommeng, F., Ikram, D., Dwimartyono, F., \& Purnamasari, R. (2019). Waktu Pulih Sadar pada Pasien Operasi dengan Menggunakan Anestesi Umum Propofol di RS Ibnu Sina Makassar sommeng. Journal of Chemical Information and Modeling, 53(9), 1689-1699. https://doi.org/https://doi.org/10.1017/CBO9781107415324.004 